\title{
An Accounting of Pathology Found on Head Computed Tomography of Road Traffic Accident (Rta) Patients in Douala, Cameroon
}

\author{
Uduma Felix Uduma (Corresponding author) \\ Department of Radiology, Abia State University Teaching Hospital \\ Aba, Nigeria \\ Tel: 234-803-745-0099Ｅ-mail: felixuduma@yahoo.com \\ Motah Mathieu \\ Neurosurgical unit, Department of Surgery, University of Douala \\ Douala, Cameroon \\ Tel: 237-7565-8643Ｅ-mail: motmath@yahoo.Fr
}

Received: August 2, 2010 Accepted: August 17, 2010 doi:10.5539/gjhs.v3n1p171

\begin{abstract}
Background: RTA is a serious concern to many developing countries with its untoward effects on the economy. In many African countries, this is due to recent invasion into transport system by motor cyclists.

Objectives: To evaluate head computed tomograms (CT) of RTA patients in Douala in order to account for pathologies.

Setting: Polyclinic Bonanjo, Douala, Cameroon is a tertiary care hospital.

Methodology: A prospective study of non-contrast head CT of RTA patients from April to November 2009 was done.

Results were evaluated with SSPS statistical version.

Results: A total of 94 Patients were studied constituting $20.84 \%$ of total number of CTs done for whatever reason. Males were more affected than females, $62(65.96 \%)$ and 32(34.04\%) respectively The highest incidence of 22 cases (23.04\%) was found in 50-59 age range with no gender difference. The next in incidence was 30-39 age range but unlike the former, a male to female ratio of 5:1 was observed. Highest percentage of cases (26.59\%) had normal brain CT scans. This could be false positive results since CT has a reduced sensitivity in detecting diffuse axonal injury and brain concussion. The commonest observed pathology (19.14\%) was brain oedema.

Conclusion: RTA in Douala, Cameroon using the percentage of brain computed tomograms as an index is common and needs government's action.
\end{abstract}

Keywords: Road traffic accident, Computed tomograms, Trauma, Brain

\section{Introduction}

Road traffic accident (RTA) has become a source of worry to many developing countries. For example in Libya, it has been considered an epidemic [Abdulmaid, 2007, 2(2)]. In Brazil, it has become a public health question. In that country, as much as 500,000 Brazilians die per year due to accidents [Pareira et al, 2002, 2(2)].

Injuries such as RTA injuries are common and on the increase in most developing countries including sub-Saharan Africa [Nordberg, 2000, pp41-43]. In a typical East African area, total rate of significant injuries is estimated at $40000 / 100000 /$ year with a large proportion due to RTA [Nordberg, 2000, pp41-43].

On a wider spectrum, 1.26 million people died world-wide in the year 2000 from RTA [Smiths et al, 2008, pp568-573].

When evaluated on yearly basis, nearly 1.2 million people are killed in RTA constituting $2.1 \%$ of global mortality and 20-50 million more are injured or disabled constituting $2.6 \%$ of all disability adjusted life years lost [Peden, 2005, pp85-91]. The young actively employed people were the most affected [Smiths et al, 2008, 
pp568-573]. Neuro-trauma (commonest cause is RTA) is common in many countries especially in the younger age groups and it kills more than AIDS or cancers but unlike these diseases, the causes are known and preventable [Reilly 2005,pp3-9].

Low and middle-income countries account for about $85 \%$ of the deaths due to RTA and $90 \%$ of the RTA disability adjusted life years lost annually [Peden,2005pp,85-92,Borse, 2009,pp321-6]. In India there is a high burden of RTA in the urban population with annual RTA mortality and disability rates of 38.2 and $35.1 \%$ per 100000 population respectively [Dandona et al, 2008, pp354-9]. The occurrence of RTA among road users has regional variations. The incidence of non-fatal RTA was highest in pedestrians, motorised 2-wheel vehicle users and cyclists at 6.4, 6.3 and 5.1/100 persons/year respectively [Dandona et al, 2008. pp354-9]. The magnitude of pedestrians fatalities range from more than half from African sub-region to $15 \%$ or less in American and European sub- regions [Naci et al, 2009, pp55-8]

In some African countries, the widespread use of motor cycle as a means of transportation has significantly raised the number of road traffic accidents. This increasing incidence is due to rapid growth of motorised transportation and industrialisation without safety precautions [Nordberg, 2000, pp41-43].

Computed tomography (CT) is considered as the first choice in the assessment of the Patients with acute head injury hence justifying the use of this radiological tool in this study [Besenski, 2002, pp1237-52, Hydel et al, 2000, pp100-5, Hofman et al, pp441-449, 2001, Manolakaki et al, 2009, pp1008-14].

This article is in response to calls for more papers on RTA from developing worlds [Borse et al, 2009, pp321-6]. Though currently there appears to be a change, but in 2001-2004, all papers in all languages on RTA, had 41\% coming from US, 36\% from Europe while North Africa and the 2 most populous Countries (India and China) had less than one article on RTA injury per 1000 RTA related deaths [Borse et al, 2009, pp321-6]. Besides, there is need for global collaboration on RTA prevention because WHO predicted that unless there are changes in present policies and if no additional safety counter-measures are put in place, there will be a major increase in RTA fatalities over the next 20 years and beyond [Peden, 2005, pp85-91, Reilly, 2007, pp3-9]. Moreover, any policy on any injury prevention and safety in developing countries will be more effective if based on local evidence and research designed to suit the social, political and economic circumstances found in those countries[Borse et al, 2009, pp321-6].

Aim: To evaluate the head computed tomograms of patients who sustained head injury in road traffic accidents in Douala with accounting of neuro-cranial traumatic pathology

\section{Materials and Methods}

A prospective study on consecutive patients who presented for head CT in Department of Radiology, Polyclinic Bonanjo, Douala on account of RTA was undertaken. A seven-and-half month period spanning from 5/4/09 to $15 / 11 / 09$ was covered. Inclusion criteria include any patient coming into the Department for head CT scans for reasons related to RTA within the period under review. The age, sex and CT findings were recorded. Patients without demographic data on their request forms and poor CT images were excluded. Such poor CT images were laden with motion artefacts precluding meaningful image evaluations and most of the patients were lost before re-booked time. All the brain CT examinations were performed with Shumadzu Spiral CT scan machine with continuous rotational system. Non- contrast axial slices of thickness $2 \mathrm{~mm}$ at the base of the skull and $5 \mathrm{~mm}$ above the sella were acquired. Re-constructed coronal and sagital images were used to assess the depth of intra-cranial bleed. Statistical data were analysed using SSPS 12.0 statistical package.

Setting: Polyclinic Bonanjo, Douala, is a foremost specialist and tertiary care hospital in Cameroon serving the commercial city of Douala and its environ.

\section{Results}

A total number of 94 Patients involved in RTA were studied. Most of the patients came from Douala and its environ. The time interval between time of trauma and scanning of patients were quite variable, ranging from two hours to 6 months. The studied population constitutes $29.93 \%$ of total number of head CT done in the hospital in the studied period. This also forms $20.84 \%$ of all CT scans done in any part of body for whatever reason. Age range of Patients involved in RTA was 0-89years.

Males were more affected than females 62(65.96\%) and 32(34.04\%) respectively. The age range most affected was 50-59 with a total of 22(23.04\%), followed by 30-39 with a total of 18(19.1\%). In the 30-39 age range, male to female ratio was 5:1 while it is $1: 1$ for 50-59 age range. $25(26 \%)$ Patients had normal CT. The highest abnormality was cerebral oedema with 18 cases $(19.14 \%)$. 
Intra-cerebral haematomas were more than extra-cerebral haematoma to a ratio of 1.3:1. Many of the intra-cerebral haematomas were multi-focal. Commonest uni-focal site was parietal (25\%). Intra-cerebral haematoma were more in males than females (3:1). Epidural -Subdural haematomas ratio is 1.6:1. Male to female ratio for epidural haematoma is $4: 1$. Frontal calvarium was the most fractured bone (33.3\%) and depressed fracture was seen in $10 \%$ of cases.

11 cases were re-booked due to poor image quality and only 3 were re-scanned. 8 of these cases were never re-imaged due to death and are not accounted for in this study with absence of CT findings.

\section{Discussion}

4.1 The availability of $\mathrm{CT}$, its rapidity of scanning, reconstructive ability and compatibility with medical resuscitatory devices underlie CT use in acute head injury imaging [Besenski, 2002, pp1237-52, Sutton et al, 2006, pp1779-1782 Onwuchekwas, 2009, pp25-31, Kirkpatrick et al, 2003, pp91-98]. CT of the head is readily obtainable in most medical centres and is the cornerstone of rapid diagnosis [Udstuen et al, 2001, pp135-47] This is pertinent since RTA Patients with head injury may be unstable and un-cooperative. This invariably mandates fast acquisition of images in seconds with equipment that is economical, easily accessible in most hospitals and simple to perform in agitated patients [Haydel et al, 2000, pp100-5Hofman et al, 2001, pp441-9Kirkpatrick et al, 2003, pp91-8Gentry et al, 1988, pp673-82].

CT is the preferred tool for skull lesions and the sensitivity of CT is significantly higher than MRI for evaluation of fracture [Orrison et al, 1994, pp351-6]. Advantageously poor quality CT images due to motion blurring are easily repeated. Head CT is the only imaging test necessary in the first 48hours after traumatic brain injury [Manolakaki et al, 2009, pp1008-14]. CT is a good screening tool to triage minor head injury so as to ascertain who should be safely discharged home or admitted [Smiths et al, 2008, pp568-73 Besenski, 2002, 1237-52, Palva et al, 2000, pp172-6, Davies, 2007, pp1619-21]. While CT is the first line examination to detect immediate life threatening lesions, MRI is first choice for full assessment of brain lesions [Braun et al, 2000, 296-8]. Despite the fact that CT is an important part of the diagnostic armamentarium in RTA neuro-cranial imaging and to date still the technique of choice for evaluation of head traumas, there are pitfalls [Hofman et al, 2001, pp441-49].

The sensitivity of MRI is significantly higher than CT in detecting diffuse axonal injury (DAI), brainstem lesions, non-haemorrhagic contusion or sub-acute subdural bleed and sinus invasion [Sutton et al, 2006, pp1779-82, Gentry et al, 1988, pp673-82, Orrison et al, 1994, pp351-56, Dahnert, 2006, pp327-329, Yokota et al, 1991, pp351-7]. Streak and beam hardening artefacts degrade images particularly lesion close to cerebral convexities. On these regards, MRI with superior soft tissue contrast and multi-planarity is more sensitive for chronic traumatic head injury, subtle abnormality and has strong correlations with long term neuro-psychological outcome [Haydel et al, 2000, pp100-5, Manolakaki et al, 2009, pp1008-14, van der Naalt et al, 1999. pp70-8]. Newer MRI techniques like FLAIR, Fast Field echo (FFE) T2W, DWI and MR Spectroscopy have further enhanced the sensitivity of MR imaging in detection of post-traumatic changes and increase correlations to neuro-cognitive deficits [Hofman et al, 2001, pp441-9].

Though CT and MRI are highly and comparably sensitive in detection of haemorrhagic intra-axial lesions and superficial soft tissue injury, MRI provides some information to evaluation of the severity of DAI, post-traumatic lesions and predictions of delayed traumatic intra-cerebral haematoma [Besenski, 2002, pp1237-52, Orrison et al, 1994, pp351-350, Yokota et al, 1991, pp351-7]. Estimation of lesion volume based on MRI were frequently greater than with CT but MRI disclosed no additional lesions that require surgical evacuation [Levin et al, 1987, pp700-13]. MRI has clear advantage over CT in evaluation of closed head trauma, lesions seen in minor traumatic brain injury (like non-haemorrhagic cortical contusion), and follow-up parenchymal changes. [Besenski, 2002, pp1237-52 Hofman et al, 2001, pp441-449, Gentry et al, 1988, pp673-82]. Longer scanning time, poor sensitivity to skull fracture and SAH as well as inability to monitor patients in the MRI fields are MRI drawbacks [Besenski, 2002, pp1237-52]

MR Spectroscopy however holds promise for the future by aiding in identification of biochemical changes that may predate morphological findings with negative CT findings [Malslehaty et al, 2010epub a head of print]. In chronic minor traumatic brain injury, SPECT is considered more sensitive than CT and MRI [[Hofman et al, 2001, pp441-9]. SPECT and PET detects abnormal lesions and focal areas of cerebral hypo-perfusion in normal CT or MRI [Hofman et al, 2001, pp441-9, Abdel Dayem, 1996, pp309-17].

4.2 In our study $20.84 \%$ of the total CT scans done for whatever indication were brain scans related to RTA. This is a high value despite the referral bias since they are other CT facilities in Douala that are also imaging neuro-cranial traumatic cases of RTA. One may be tempted to argue that this single centre study is a limitation to 
hypothesizing that RTA is high in Douala, the commercial capital of Cameroon. Rather it is a corroborating factor, considering the fact that a single health institution in the midst of others offering same CT imaging services to Douala and its environ could record such a value. Moreover many more patients could have been unaccounted for since there is no helicopter services in the country to ferry RTA patients to hospitals. Though this has been substituted by ambulance services but many more patients cannot afford CT imaging due to poverty. Also some re-booked cases because of poor CT images resulting from patients' aggressiveness with contraindication to sedation died before re-appointment time. All the above patients were also not accounted for in this study, further diluting our value of RTA incidence. Based on the foregoing, our recorded value in this study connotes an index of high rate of RTA in Douala, Cameroon. This needs urgent government action because without appropriate actions by 2020, RTA injuries are predicted to be the third leading contributor to the global burden of diseases [Peden, 2005, pp85-91].

RTA is the commonest cause of traumatic death in Africa [Hawryluk et al, 2010, online]. In Cameroon, RTA occurrence is not un-connected with poor road networks and socio- attitudinal changes like alcoholism. In this study, the age range most affected is 50-59years with no gender difference. This is obvious because in most African settings men seem to relinquish their bread winning responsibilities to their wives with increasing age. These women travel to villages on dilapidated roads in a rickety overloaded motors. The next highest rate is 30-39 age range involving young actively employed people with high mobility. Patient with trauma tend to be a young actively employed population that often moves [Smiths et al, 2008 pp568-573, Dahnert, 2006, pp354-9]. The latter reason and significant activity in family sustenance accounts for the male preponderance in this age range [Smiths et al, 2008, pp568-573].

Most patients have normal brain CT findings. This possibly include false negatives as CT is insensitive to concussion, diffuse axonal injury (DAI), early cerebral oedema and has poor resolution in imaging of posterior cranial fossa [Besenski, 2002, pp1237-52, Onwuchekwas, 2009, pp25-31, Tandon, 2001. pp3-10]. Such cortical contusions and DAI are under-estimated by CT but best depicted by MRI [Hofman et al, 2001, pp441-9, Yokota et al, 1991, pp351-7]. Head CT images obtained immediately after the traumatic event often show no evidence of brain swelling or oedema but practically normal [Buadu et al, 2010, online]. CT focuses on moderate to severe brain injury, because of limited sensitivity but is widely used as screening test in patients with minor head injury, although the results are often normal [Haydel et al, 2000, pp100-5, Hofman et al, 2001 pp441-9] Approximately $2 / 3$ of patients with head trauma in US are classified as minor head injury, less than $10 \%$ of such patients have positive findings on CT scanning, implying that greater than $90 \%$ had normal CT findings [Haydel et al, 2000, pp100-5]. If CT done can not demonstrate pathology as can adequately be explained to account for clinical state MRI is warranted [Besenski, 2002, pp1237-52, Manolakaki et al, 2009, pp1008-14].

DAI is seen in up to $50 \%$ of trauma and suspected when alteration of mental state is out of proportion to the CT findings [Tandon, 2001, Coles, $2007 \mathrm{pp3-10]}$. DAI is due to rotational acceleration-deceleration force of RTA causing cerebral cortex to move at different speed from the deep white mater [Besenski, 2002, pp1237-52, Tandon, 2001, 3-10].. In DAI, multiple, bilateral, microscopic, punctate and petechial haemorrhages are seen at classical sites like grey-white mater interface, corpus callosum especially the splenium, dorsal upper brain stem and cerebellum [Smiths et al, 2008, 568-573, Davies, 2007, pp1619-1621, Tandon, 2001, 3-10, Rainer, 2003, pp1049-50]. These micro-bleeds which measure $1-5 \mathrm{~mm}$ are tissue tear haemorrhages and their number has a correlation to patients Glassglow coma scale [Rainer, 2003, pp1049-50]. Because of the superior conspicuity provided, T2 ${ }^{*} \mathrm{~W}$, gradient echo, and FLAIR are preferred MRI techniques for demonstrating DAI [Buadu et al, 2010, Rainer, 2003, pp1049-50]. Any unconsciousness lasting more than 6hours raises suspicion of DAI and absence of lucid interval is its hallmark [Tandon, 2001, pp3-10]: But when unconsciousness is less than 6hours it suggests concussion. $11 \%$ of all patients with DAI have been reported to have associated intra-cerebral haematoma. [Tandon, 2001, pp3-10]

Brain injuries include either extra-cerebral and intra-cerebral lesions. The former requires rapid diagnosis and treatment and the latter determines management in an intensive treatment unit and outcome [Braun et al, 2000, pp296-8]. The commonest pattern of intra-cerebral haematoma in our study was multi-focal. The commonest uni-focal site was in the parietal lobe. The incidence of intra-cerebral haematoma in our study was $12 \%$ against $10 \%$ in a study [Hawryluk et al, 2010, online]. Intra -cerebral haematoma is differentiated from contusion if blood makes up to two-third of the lesions and the bleed is well defined [Hawryluk, 2010]. Contusion may be haemorrhagic or non-haemorrhagic accounting about $45 \%$ of primary intra-cerebral traumatic lesions. It is presents in nearly half of moderate and severe closed injury [Hawryluk et al, 2010, online].

In our study cerebral oedema is the predominant lesion with $19.14 \%$. Brain oedema is a consequence of increased brain water (vasogenic or cytotoxic) and may occur as a response to direct focal injury such as cerebral 
contusion or diffuse primary injury such as DAI [Buadu et al, 2010, online],. Contusion could be coup when lesion is below the region of cranial impact or contre-coup when lesion is distant though not always contralateral [Hawryluk et al, 2010, online].

Subdural haematoma is the crescent shape collection between the dura and the arachnoid which can cross sutures but not dura [Dahnert, 2006, pp327-29]. It is due to disruption of bridging veins between the surface of the brain and the venous sinuses. This makes it more common in patients with brain atrophy and alcoholics [Dahnert, 2006, pp327-9]. Its aetio- pathogenesis is such that it is concurrent with other brain lesions like laceration and contusion. This raises its mortality to more than $50 \%$ which is un-acceptable [Hawryluk et al,2010,online]. Epidural -Subdural haematomas ratio in this study is 1.6:1 making subdural haematoma less in incidence than epidural haematoma. This is a reversal of some recorded trends of higher incidence of subdural haematoma than epidural haematoma of all head trauma [Dahnert, 2006, pp327-9]. This reversal may be that RTA patients with minor head injury which is more associated with subdural haematoma probably do not bother seeking immediate medical help in a poor African setting. Besides some CT images may be false negative due to high -convexity location of such bleed. Also it may be due to beam hardening artefacts, volume averaging with high density of calvarium obscuring flat en plaque sub-dural haematoma [Dahnert, 2006, pp327-9]. Additional reasons are presence of isodense subacute subdural haematoma (due to delaying in imaging 10-20 days post-injury ), low haemoglobin content of blood, lack of clotting or CSF dilution from associated arachnoid tear [Dahnert, 2006 pp327-9].

Epidural haematoma, the commonest extra-cerebral haematoma in our study was seen more in young people with male pre-ponderance. Epidural haematoma which occurs in $6 \%$ of head injury is seen as a lens shaped collection between the inner surface of the skull and the stripped dura [Hawryluk et al, 2010, online]. It can cross dura but not suture and is usually associated with skull fracture. $70 \%$ of epidural bleed is seen in the temporal and temporo-parietal bone, $10 \%$ in frontal, $10 \%$ parieto-occipital and $10 \%$ are infra-tentorial but less frequently in the clivus [Pareira et al, 2002, 2(2)]. Lucid interval is seen in 10-15\% of cases and mortality is doubled if it is absent. $70 \%$ of patients may require surgery with good outcome and mortality is as low as $5 \%$ [Pareira et al, 2002, 2(2)].

Soft tissue injury was commonest in the parietal region corresponding to high rate of parietal intra-cerebral haematoma in our study. But the commonest site of calvarial fracture in this study was frontal bone. This is probably due to reduced thickness and weight of this bone resulting from intra-osseous interposition of air of para-nasal sinus [Yasuda et al, 2007, pp466-472]. Depressed fracture and traumatic subarachnoid bleed were not common in our study. Depressed fractures include all fracture of the skull vault in which inward displacement of at least one of the bone fragments was seen [Smiths et al, 2008, pp568-73]. CT with Thin slices and bone windows are requisites to display depressed fracture [Braun et al, 2000, 296-8].

Traumatic SAH is common and it is concomitant to cerebral contusion [Dahnert, 2006, pp327-9]. Its aetio-genesis is due to rupture of either lepto-meningeal vessels at vertex or major intra-cerebral vessels (less common)[Dahnert, 2006, pp327-9]. Traumatic sub-arachnoid haematoma is more typically located in the cerebral convexities against basal cistern location seen in aneurysm [Dahnert, 2006, pp327-9]. Location of traumatic SAH are (a) focal, overlying site of contusion/ subdural haematoma (b) inter-hemispheric fissure, paralleling falx cerebri with dentate margins (c) spreading diffusely through -out sub-arachnoid space ( rare in trauma )[Dahnert, 2006, pp327-9]. SAH can be classified into 3 groups namely (a) patients with normal CT and diagnosis made by lumbar puncture. (b) patients with a pure peri-mesencephalic pattern (c) patients with bleeding pattern resembling that of aneursymatic rupture [Brauin et al, 2000, 296-8]. However there is no specific clinical syndrome that can differentiate patients who have a peri-mesencephalic SAH pattern caused by aneurysms from those without aneurysms [Alen et al, 2003, pp529-35]. CT is mandatory for detecting SAH while digital substraction angiography is for visualising vascular pathology [Brauin et al, 2000, pp296-8, Karttunri et al, 2003, pp655-61, van Cojn et al, 2001, pp249-78]. Outcome is excellent for SAH patients with normal CT or peri-mesencephalic pattern [Davies, 2007, pp1619-142]. The recovery rate and daily life activities evaluated using Glassglow outcome scale score were lower in patients with intra-ventricular bleed [Levin et al, 1987]. The mortality rate is proportionally greater in patients who had cisternal clots $>1 \mathrm{~mm}$ [Davies, 2007, pp1619-142]. Complications of SAH are recurrent haematoma, intra-cranial haemorrhage, hydrocephalus and global brain ischemia [van Cojn, 2001. pp249-78]

RTA is a major health and developmental problem [Gentry et al, 1988, pp673-82]. The cost to communities in terms of suffering and economics are enormous [Peden, 2005, pp82-91, Reilly, 2007, pp3-9]. Total costs of RTA casualties in Barcelona in 2003 were EURO 367million with $89.8 \%$ being direct costs like property damage, insurance, admission, Police emergency and transportation costs [Carcia-Altes et al, 2007, pp65-8]. Indirect cost 
were 37million EURO including lost productivity due to hospitalisation and mortality [Carcia-Altes et al, 2007, pp65-8]. Overall global annual costs were estimated in the late 1980s at around 500 billion US dollars [Nordberg, 2000, 41-43]. Globally, its estimated that 518billion US dollars is spent on RTA with low and middle income countries accounting for 65 billion US dollars which is worse than these countries receive on developing assistance [Peden, 2005, pp87-91]. Neuro-trauma effects are particular in developing worlds where it consumes already over stretched health resources [Reilly, 2007, pp3-9]. Africans are known to carter for their own immediate family and distant family members, therefore everyone killed or injured or disabled by RTA, there are countless others deeply affected. Many families are driven into poverty by the expenses of prolonged medical care, loss of family breadwinner or the added burden of caring for the disabled [Peden, 2005, pp85-91].

\section{Conclusion}

Road traffic accidents(RTA) appear common in Douala, Cameroon taking into cognizance the percentage of brain computed tomograms done in our centre as result of RTA alone. This is invariably accompanied by traumatic head injury which affects mostly the young people with consequent negative effect on the active work force and economy.

\section{Recommendation}

(a) Good road networks, road safety enlightenment campaign and establishment of neuro-trauma centres are pertinent.

(b) Legislation and enforcement of road safety codes.

(c) Funded concurrent multi-centre national study should be encouraged.

\section{References}

Abdel-Dayem, H. M., Abu-Judeh, H., Kumar, M., Atay, S., Naddar, S., El-Zeftaway, H. \& Luu, J.Q. (1996). Perfussion abnormalities in mild or moderate traumatic brain injury. Clin Nucl. Med. 23 (5), 309-17.

Abdulmaid, A. A. (2007). Road Traffic Accidents. The number one killer ln Libya. Libyan Journal of Medicine; 2 (2):AOP:070827.

Alen, J. F., Lagares, A., Lobato, R. D., Gomez, P. A., Rivas, J. J., \& Ramos, A. (2003). Comparison between Peri-mesencephalic non-aneursymal sub-arachnoid haemorrhage caused by posterior circulation aneurysms. $J$ Neurosurg. (3), 529-35.

Besenski, N. (2002). Traumatic injuries: imaging of head injuries. Eur Radiol. 12 (6), 1237-52.

Borse, N. N., \& Hyder, A. A. (2009). Calls for more research on injury from the developing world: results of a bibliometric analysis. Indian J Med Res. 128 (3), 321-6.

Braun, M., Cordoliani, Y.S. \& Dosch, J. C. (2000). [Head and brain injuries, place of imaging]. Ann Fr Anesth Reamin. 19 (4), 296-8.

Buadu, L., Ekholm, S., Lenane, A., Moritani, T., Hiwatashi, A., \& Westesson, P. L. (2010). Pattern of head injury in non-accidental trauma. [Online] Available http: www. Neurographics.org 2/1/2/L. Shtml (August 22, 2010).

Carcia-Altes, A. \& Perez, K. (2007). The economic cost of road traffic crashes in an urban setting, Inj Prev. 13 (1), 65-8.

Coles, J. P. (2007). Brain Injury. British Journal of Anaesthesia, 99,(1), 49-60.

Dahnert, W. (2006). Radiology review manual, ( $6^{\text {th }}$ ed.), Phildelphia, Wolters Kluwer/ Lippincort Williams \&Williams, 286, 327-329

Dandona, R., Kumar, G. A., Amear, M. A., Ahmed, G. M., \& Dandonna L. (2008). Incidence and burden of road traffic injuries in urban India, Inj Prev, (6), 354-9

Davies, P. C. (2007). Head Trauma. American Journal of Neurology. 28, 1619-1621.

Gentry, L. R., Godersky, J. C., Thompson, B., \& Dunn, V. D. (1988). Prospective comparative study of intermediate field MR and CT in the evaluation of closed head trauma, AJR Am Roentgenol, 150 (30, 673-82.

Haydel, M. J., Preston, C. A, \& Du Blieux M. C. (2000). Indications for CT in minor head injury, NEJM. 343, 100-105.

Hawryluk, G. \& Bernstein M. (2010). Traumatic Brain injury-management in Africa, Africa monthly Review [Online] Available: Brodel.med.utoronto.ca/NEURO/neurosurg/volume8_3.htm (Febuary 13, 2010). 
Hofman, P. A. M., Stapert, S. Z., van Kroonenburg J. P. G., Jolles J, \& Wilmink J. T. (2001). MR imaging singleton photon emission CT and neurocognitive performance after mild traumatic brain injury. AJNR. 22 (3), 441-449.

Karttunri, A. I., Jariti, P. H., Ukkda, V. A., Sajanti, T \& Haapea, M. (2003). Value of the quantity and distribution of sub-arachnoid haemorrhage on CT in the localisation of a ruptured cerebral aneurysm. Acta, Neurochir (Wien). AF 145 (8), 655-61.

Kirkpatrick, I. D. C., Kroeker, M. A., \& Greenberg, H. M. (2003). Biphasic CT with Mesenteric CT Angiography in the Evaluation of Acute Mesenteric Ischaemia; Initial Experience, Radiology, 229, (1), 91-98.

Levin, H. S., Amparo, E., Eisenberg, H. M., Williams, D. H., High, W. M. Jr., Mc Ardle, C. B., Weiner, R. L. (1987). Magnetic resonance imaging and computerised tomography in relations to neuro-behavioural sequlae of mild and moderate Head injuries. J Neurosurg. 66 (50, 706-13.

Malslehaty, H., Petrich, A. K., Barth, H., \& Mehdonas, H. M. (2010). Diagnostic value of magnetic resonance imaging in peri-mesencephalic and non peri-mesencephalic sub-arachnoid haemorrhage of unknown origin. $J$ Neurosug [Epub a head of print]

Manolakaki, D., Velmahos, G. C., Spaniolas, K., de Moya, M. \& Alam, H. B. (2009). Early magnetic resonance imaging is unnecessary in patients with traumatic brain injury. J Trauma, 66 (4), 1008-14.

Naci, H., Chisholm, D. \& Baker, T. D. (2009). Distribution of road traffic deaths by road user group: a global comparison. Inj Prev, 15 (1), 55-8.

Nordberg, E. (2000). Injuries as a public health problem in Sub-saharan Africa: epidermiology and prospects for control. East Afr Med J. 77 (12 Suppl) S1-43.

Onwuchekwa, R. C., \& Onwuchekwa, A. C. (2009). Computerised Tomography of the Brain Findings in Stroke Patients at the University of Port Harcourt Teaching Hospital. West African Journal of Radiology, 16, (1), 25-31.

Orrison, W. W., Gentry, L.R., Stimac, G.K. Tarrel, R.M., Espinosa, M. C., \& Cobb, L.C. (1994). Blinded comparison of cranial CT and MRI in closed head injury evaluation. AJNR, 15 (2), 351-356.

Palva, W. S., de Andrade, A. F., de Amorim, R. L., Muniz, R. K., Paganelli, P. M., \& Bernardo, L. S. et al. (2000). The prognosis of the traumatic sub-arachnoid haemorrhage, a prospective report of 121 patients. Int Surg. 95 (2), 172-6

Pareira, C. U., Domingo, S. J., Leao, B. C., \& Ribes, A., et al. (2002). Frontal Epidural Haematoma: Analysis of 30 cases; The Internet Journal of Medicine, (2) 2 ISSN 935-955.

Peden, M. (2005). Global collaboration on road traffic injury prevention. Int J. Inj Contr Saf Promot. 12 (2), 85-91.

Rainer, S.. Cristoph, P., Oliver, G., Christopher, W., \& Yves von Cramon D. (2003). Diffuse axonal injury associated with chronic traumatic brain injury: Evidence from T2* Weighted gradient echo imaging at 3T. AJNR, 24, 1049-1050.

Reilly P. (2007). The impact of neurotrauma on society: an international perspectives. Prof Brain Res. 161, 3-9.

Smiths, M., Hunink, M. G. M., Van Rijssel, D. A., \& Dikker H M et al. (2008). Outcome after complicated minor head injury. American Journal of Neurology. 29,568-573.

Sutton, D., Stevens, J. \&, Miszkiel, K. (2006). Intracranial lesions (2) In Sutton, D., (7 $7^{\text {th }}$ ed)Textbook of Radiology and Imaging, vol 2, Phildelphia Elsevier Church ill Livingstone, 1779-178.

Tandon, P. N. (2001). Acute subdural haematoma: Reapprissal. Neurology. 49, 3-10.

Udstuen, G, J., \& Claar, J. M. (2001). Imaging of acute head injury of acute head injury in the adult. Semin Ultrasound, CT, MR (2), 135-47.

van der Naalt, J., Hew, J. M., van Zomeren, A. H., Sluiter, W. J., \& Minderhoud, J. M. (1999). Computed tomography and magnetic resonance imaging in mild to moderate head injury: early and late imaging outcome. Neurol. 46, 70-8.

Van Gijn, J, \& Rinkel, G. J. (2001). Sub-arachnoid haemorrhage: Diagnostic causes and management: Brain 124 (2), 249-78.

Yasuda, M., Nissato, N., Miyazaki, H., Hama, T., et al. (2007). Epithelial ion transport of Human nasal polyp and Paranasal Sinus Mucosa, American Journal of Respiratory cell and Mollecular biology. 36, 466-472. 
Yokota, H., Kurokawa, A., Otsuka, T. Kobayashi, S., Nakazawa, S. (1991). Magnetic resonance imaging in acute head injury. J. Trauma, 31 (3), 351-7.

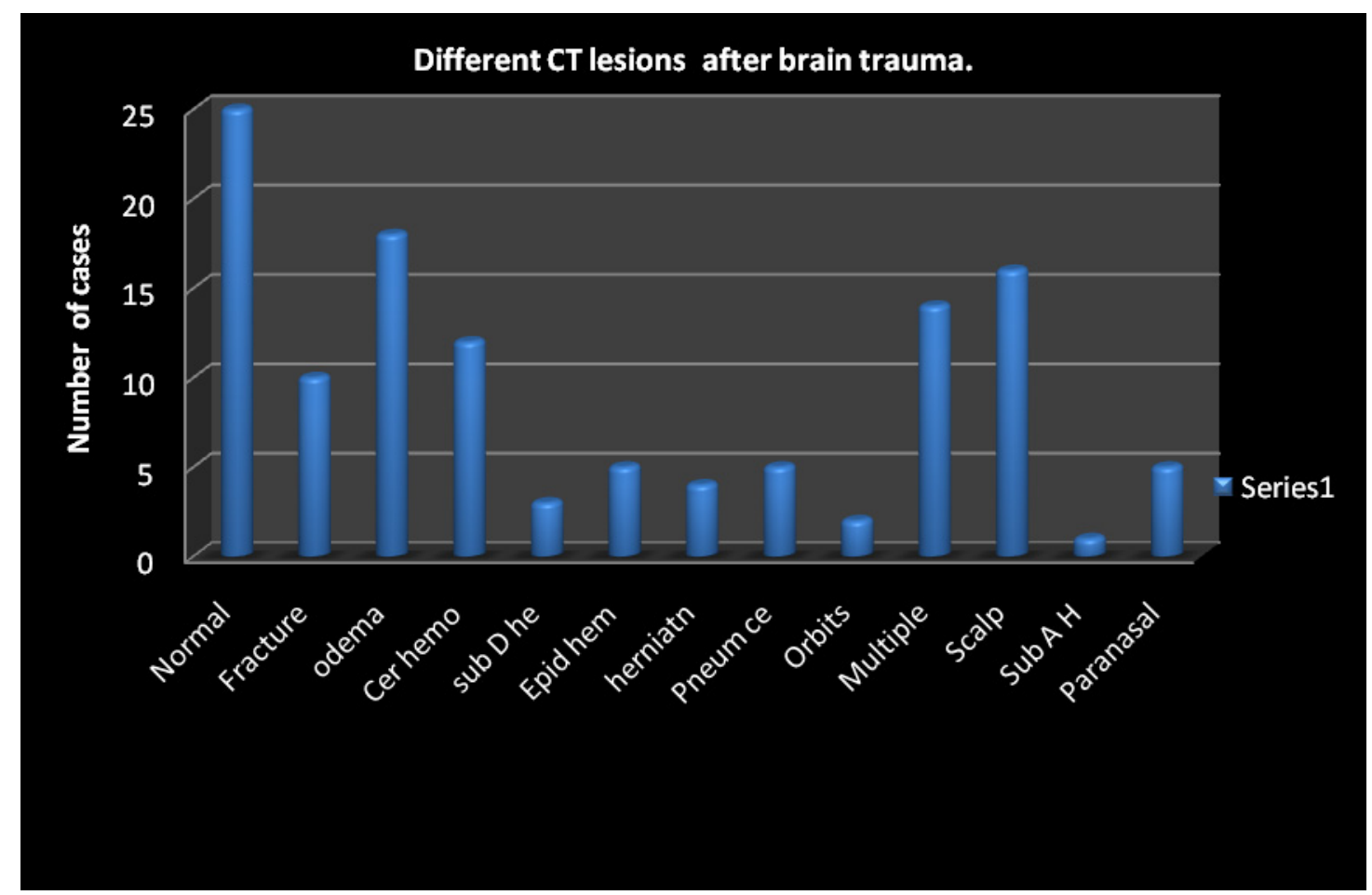

Figure 1.

Gender comparism of CT Head injury (RTA) for different age ranges.

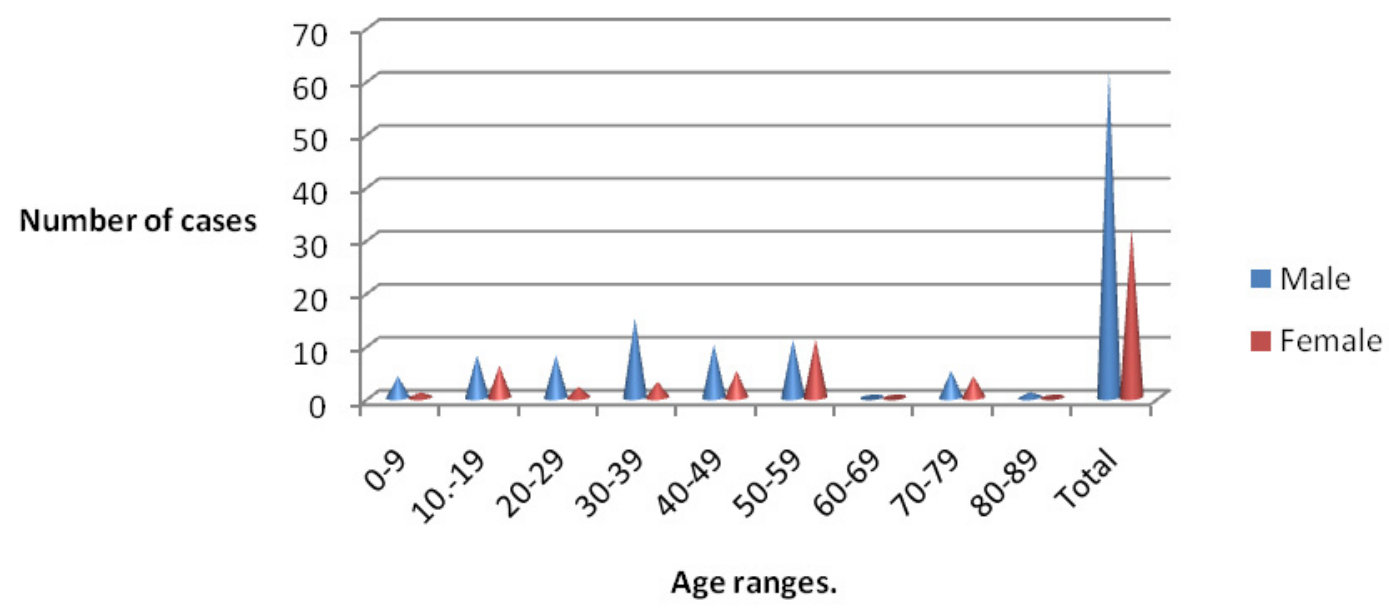

Figure 2. 


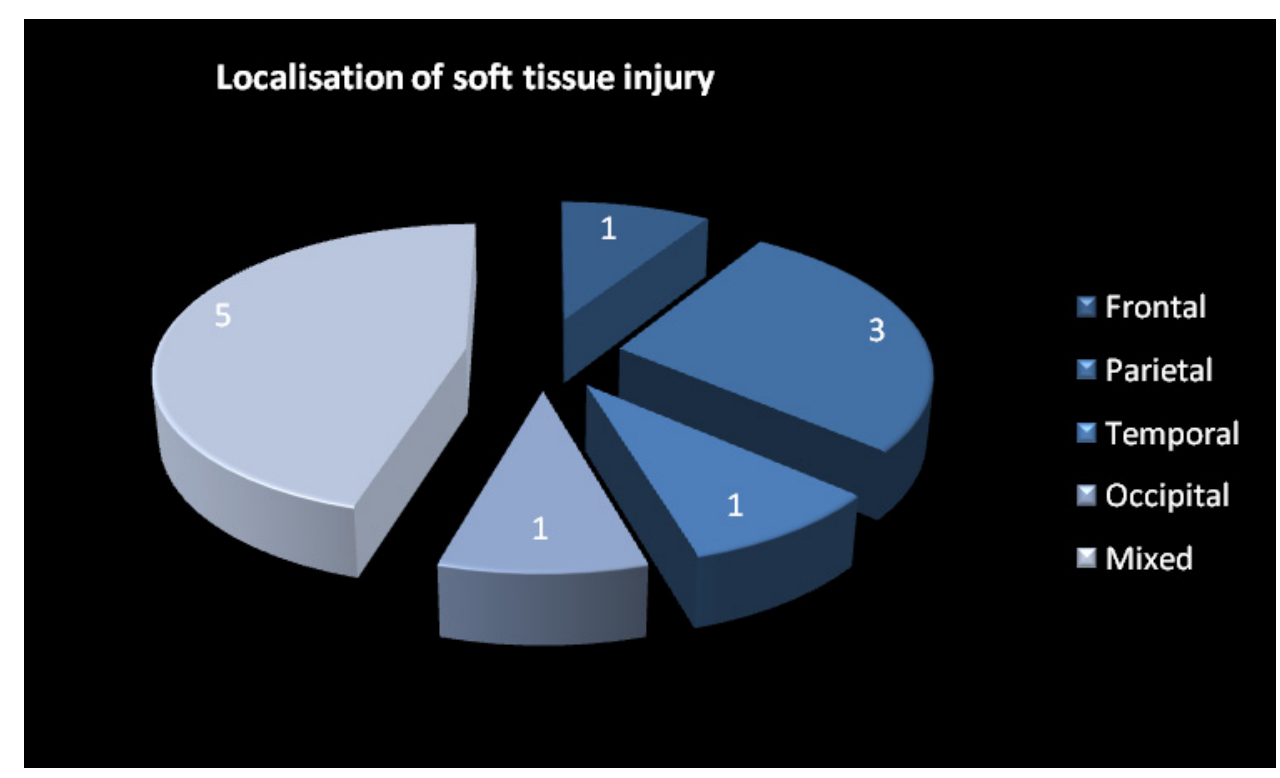

Figure 3.

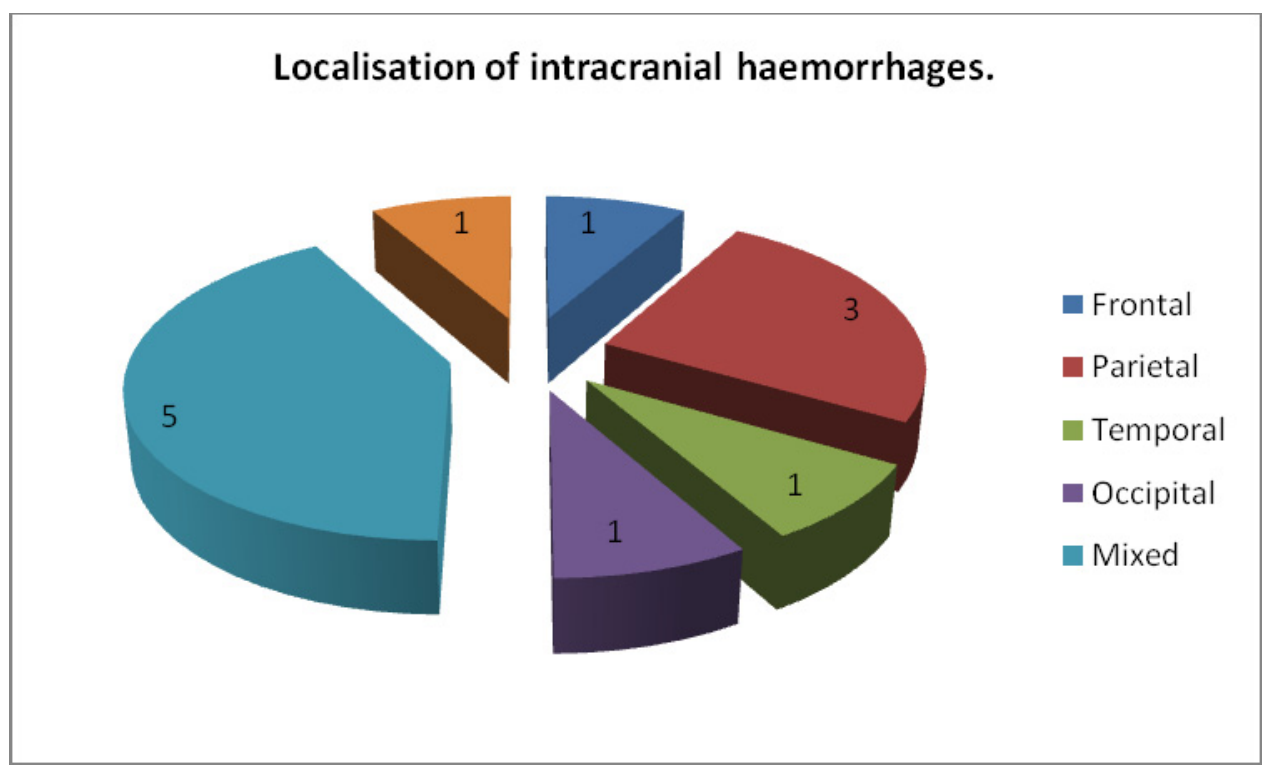

Figure 4. 


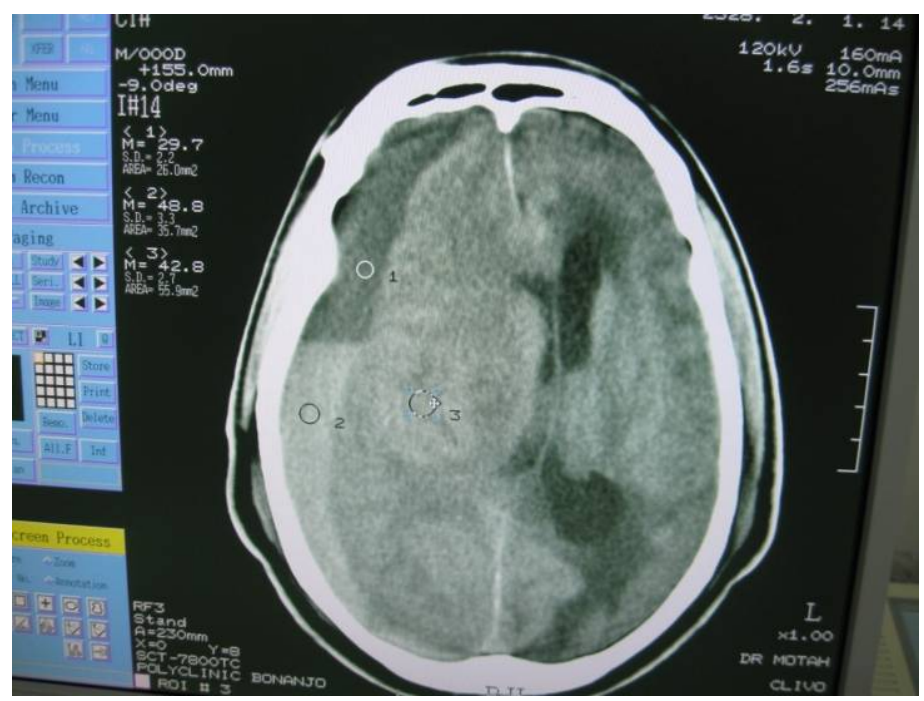

Figure 5. Axial CT image showing Acute on chronic right sub-dural haematoma

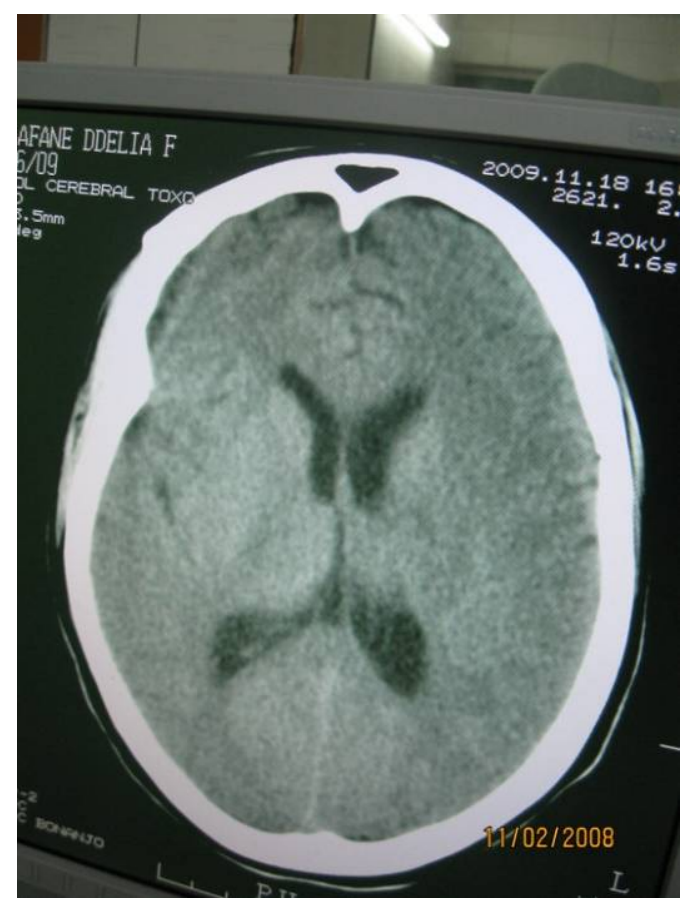

Figure 6. Diffuse cerebreal oedema with loss of cortical sulci, worse posteriorly 